\title{
Decarbonization pathways and energy investment needs for developing Asia in line with 'well below' $2^{\circ} \mathrm{C}$
}

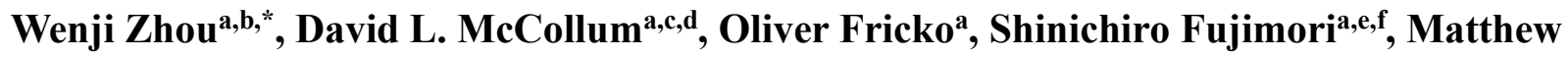 \\ Gidden $^{\text {a }}$, Fei Guo ${ }^{\text {a }}$, Tomoko Hasegawa ${ }^{\text {a,f,g, Han Huang }}$, Daniel Huppmann ${ }^{\text {a }}$, Volker Krey ${ }^{\text {a,i, }}$ \\ Changyi Liu ${ }^{h}$, Simon Parkinson ${ }^{a, j}$, Keywan Riahi, ${ }^{a, k, l}$, Peter Rafaja, Wolfgang Schoepp ${ }^{a}$, Fang \\ Yang $^{\text {h, Yuanbing Zhou }}{ }^{\mathrm{h}}$
}

a International Institute for Applied Systems Analysis (IIASA), Schlossplatz 1 - A-2361 Laxenburg, Austria

b Department of Manufacturing and Civil Engineering, Norwegian University of Science and Technology (NTNU), Teknologivn 22, 2815 Gjøvik, Norway

${ }^{c}$ Electric Power Research Institute (EPRI), 3420 Hillview Avenue, Palo Alto, CA 94304, USA

${ }^{\mathrm{d}}$ University of Tennessee, 1640 Cumberland Avenue, Knoxville, TN 37996, USA

e Department of Environmental Engineering, Kyoto University, C1-3-361, Katsura-Campus, Nishikyoku, Kyoto, Japan

${ }^{\mathrm{f}}$ Center for Social and Environmental Systems Research, National Institute for Environmental Studies (NIES), 16-2 Onogawa, Tsukuba, Ibaraki 305-8506, Japan

g Department of Civil and Environmental Engineering, Ritsumeikan University, 1-1-1, Nojihigashi, Kusatsu, Shiga, Japan

${ }^{\text {h }}$ Global Energy Interconnection Development and Cooperation Organization, No. 8 Xuanwumennei Street, Xicheng District, Beijing 100031, P.R. China

i Industrial Ecology and Energy Transitions Programmes, Norwegian University of Science and Technology (NTNU), NO-7491 Trondheim, Norway

${ }^{\mathrm{j}}$ Institute for Integrated Energy Systems, University of Victoria, PO Box 1700 STN CSC, Victoria BC V8W 2Y2, Canada

${ }^{\mathrm{k}}$ Graz University of Technology, Inffeldgasse, A-8010 Graz, Austria

${ }^{1}$ Colorado School of Mines, 1500 Illinois Street, Golden, CO 80401, USA

Corresponding Author:

Wenji Zhou, E-mail: wenji.zhou@ntnu.no 


\begin{abstract}
Exploring potential future pathways for developing Asia's energy consumption, $\mathrm{CO}_{2}$ emissions and infrastructure investment needs is essential to understanding how the countries of this rapidly growing region may contribute to the global climate targets set out in the 2015 Paris Agreement. To this end, this study employs the state-of-the-art global integrated assessment model MESSAGEix-GLOBIOM to investigate mid-century decarbonization strategies for developing Asia to 2050. Our results indicate that a radical change in the energy portfolio is required to reach the target of 'well below' $2^{\circ} \mathrm{C}$. Specifically, our scenarios point to a rapid reduction of fossil fuel utilization, enhancement of low-carbon energy supply, and boosting of energy efficiency efforts. Such a transformation leads to a deep cut in $\mathrm{CO}_{2}$ emissions by $78 \%$ and $93 \%$ by 2050 in scenarios consistent with the $2^{\circ} \mathrm{C}$ and $1.5^{\circ} \mathrm{C}$ targets, respectively. Electricity generation and final energy consumption become dominated by low-carbon energy by 2050 in these scenarios. In terms of investment needs beyond a baseline scenario, the $2^{\circ} \mathrm{C}$ and $1.5^{\circ} \mathrm{C}$ pathways imply that the scale of low-carbon investment may need to double and triple, respectively. These increases would be partially offset by disinvestment in coal, oil and natural gas extraction and conversion infrastructure. Decarbonizing the energy system also impacts the capital needed for making progress on other sustainable development goals (SDGs), such as air pollution, clean water and food security.
\end{abstract}

\title{
Keywords
}

Investment strategies; integrated assessment; energy scenarios; climate change policies; sustainable development

\section{Key policy insights}

- Governments will need to employ a variety of policy mechanisms, including mandates and subsidies for renewables and electric vehicles, efficiency standards for end-use technologies, and bans on free-emitting fossil fuel plants, among others.

- Relative to the baseline scenario for developing Asia, the scale of investment into low-carbon energy to 2050 may need to double for a $2^{\circ} \mathrm{C}$ scenario, and to triple for $1.5^{\circ} \mathrm{C}$. Policy instruments 
such as green finance are essential for this region to mobilize a broadened channel of investment, particularly from the private sector.

- Low-carbon investment would significantly reduce the capital investment needed to achieve the SDG target for air quality, but increase the requirements for meeting targets on clean water and food security, though only to a small extent.

\section{Introduction}

The multi-dimensional targets defined by the 2015 Paris Agreement and UN Sustainable Development Goals (SDGs) imply the need for drastic changes in energy investment patterns over the coming decades, both in total volume and composition (Hasegawa et al., 2018; McCollum et al., 2018a; McCollum et al., 2018b). National policies also shape the landscape of energy investments in important ways. Developing Asia encompasses three major economic blocs, including China, India and Southeast Asia and other countries (SEAO) ${ }^{1}$. With 52\% of the world's total population, in 2018/2019, developing Asia constituted 23\% of the world's economic output (World Bank, 2018), consumed 36\% of the total primary energy and contributed $42 \%$ of the global $\mathrm{CO}_{2}$ emissions (BP, 2019). Energy consumption and $\mathrm{CO}_{2}$ emissions in developing Asia have undergone dramatic increases since the early 1990s (Figure 1). Fossil fuel still dominates the energy mix in this region. In 2018, coal contributed 52\% of the total primary energy consumption, and oil and gas combined 35\% (BP, 2019). Despite this dominance of fossil fuels, the past decade has witnessed the rapid development of renewable energy, with an average growth rate of $10.6 \%$ per annum. Driven by rapid economic growth fueled by carbon-intensive fossil fuel-based energy, $\mathrm{CO}_{2}$ emissions from developing Asia have been growing fast over the past decades.

\footnotetext{
${ }^{1}$ Detailed sub-region definition of developing Asia in this study is provided in the Supplementary Information (SI).
} 

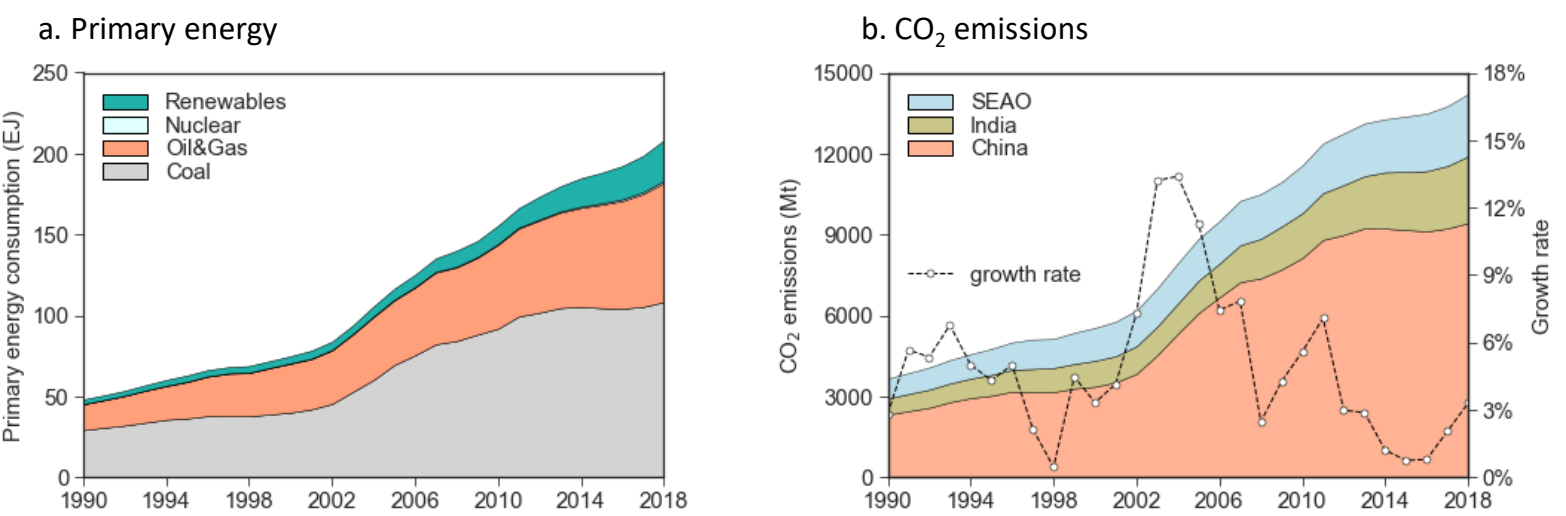

Fig. 1 Primary energy consumption and $\mathrm{CO}_{2}$ emissions of developing Asia from 1990 to 2018. Data source: BP statistics (BP, 2019)

The countries in developing Asia collectively invested US\$ 534 billion into the energy sector in 2018, accounting for roughly $28.9 \%$ of the world's total energy investment (IEA, 2019). China made up the largest share of these investments within the region (roughly two thirds), while India and SEAO split the remainder more or less evenly. In terms of the investment portfolio, the three sub-regions varied considerably: whereas investments into fossil fuel extraction (including coal mining and oil and gas extraction) in China have been declining and renewables have been growing, fossil fuel investments continue to dominate in India and SEAO. China's investments into solar, wind and large hydro generation technologies have been experiencing explosive growth. For example, China's total installed capacity of solar energy increased from 0.8 gigawatt (GW) in 2008 to $131 \mathrm{GW}$ in 2017 - a more than 160-fold increase (China Electricity Council, 2018) - making it the largest country for solar energy production in the world. Meanwhile, investments into domestic fossil fuel extraction (including coal mining and oil and gas extraction) in China have declined since 2013 (China National Bureau of Statistics, 2017). Net imports of oil and gas in China are still increasing, but with a declining trend of net imports of coal (BP, 2019). In contrast, renewable investments have been far smaller in India and SEAO, where investments in extraction and utilization of fossil fuels continue to dominate. Electricity transmission and distribution (T\&D) network investments were considerable in all three sub-regions, indicating tremendous efforts in recent years to electrify the energy infrastructure of developing Asia.

Given its great development potential, a deep understanding of the possible decarbonization pathways of developing Asia and the associated investment needs is therefore imperative, if the world is to fulfill the targets of the Paris Agreement and SDGs. To this end, integrated assessment models (IAM) offer a suitable tool to accommodate climate policy making in a prospective analytical framework. This study employed the state-of-the-art global IAM MESSAGEix-GLOBIOM (hereafter MESSAGE) to design 
four climate policy scenarios aimed at informing policy-makers and other stakeholders regarding the shifts in the energy investment landscape that are required in the region to meet the Paris Agreement goals, and how these shifts might simultaneously affect the capital requirements for making progress on other SDGs.

\section{Literature review}

Many country-level studies have investigated energy and emission scenarios for large emitting countries in developing Asia, such as China and India. Yet developing Asia -dedicated research and cross-country comparison is absent in terms of emission pathways and investment assessment. A few studies have examined the role of Asia as a whole in mitigating climate change, without distinguishing the developing countries from the developed ones in the region. For example, the Asia modeling exercise (AME), carried out by a group of IAM teams in 2012, conducted cross-model analysis on future energy use and emissions in scenarios stressing the effect of urban and rural development, the role of technology in emissions mitigation and national climate policies (Blanford et al., 2012; Calvin et al., 2012; Fujimori et al., 2017). However, the new considerations from the Paris Agreement and the SDGs have not been incorporated into these studies, which were undertaken years previously.

Another ensemble of studies have examined the driving forces underlying the historical development of energy and emissions in developing Asia countries, amongst which China's slowdown in emissions growth since 2013 have been investigated by many studies (He, 2017; He et al., 2010; Jackson et al., 2015; Korsbakken et al., 2016; Mittal et al., 2016; Qi et al., 2016; X. Zhang et al., 2016). In 2014, China's coal use dropped for the first time in two decades, by $2.9 \%$ on a yearly basis from 82.4 exajoules (EJ) in the previous year, leading to stagnation of the total energy consumption as well as $\mathrm{CO}_{2}$ emissions. In 2016, for instance, China's total primary energy consumption stood at 127.7 exajoules (EJ), just $1.4 \%$ higher than the year before (China National Bureau of Statistics, 2017). Some literature has discussed structural changes in China in depth (Guan et al., 2018; Mi et al., 2017; W. Zhang et al., 2016). This decline in coal use also contributed to a significant decrease in global $\mathrm{CO}_{2}$ emissions growth relative to the decade prior (Jackson et al., 2015). Some studies argued that China's coal use may have reached its peak because of slowing GDP growth, a structural shift away from heavy industry, and more proactive

policies on air pollution and clean energy (Qi et al., 2016; Rafaj and Amann, 2018). In contrast with the recent slowdown of China's emissions growth, India and SEAO have still been experiencing a marked growing trend of carbon emissions, at annual rates since 2013 of $5.3 \%$ and $3.1 \%$, respectively.

Despite the policy insights gained, the need for forward-looking analysis has not been addressed by 
these retrospective studies, particularly regarding the commitments made by developing Asia countries in the form of their Nationally Determined Contributions (NDC) under the Paris Agreement. These commitments include China's pledge to peak its $\mathrm{CO}_{2}$ emissions by around 2030, making its best effort to achieve this goal earlier, and to reduce carbon intensity by $60-65 \%$ by 2030 relative to the level in 2005 (China National Development and Reform Commission, 2015), along with India's commitment to reduce the emissions intensity of its GDP by 33-35\% from 2005 levels by 2030 (UNFCCC, 2015). Questions regarding the implications of these NDCs for future emissions, and the extent of the gaps with the Paris Agreement's targets of limiting warming to well below $2^{\circ} \mathrm{C}$ and pursuing efforts to $1.5^{\circ} \mathrm{C}$, remain unanswered.

To address these unknowns, this study takes into account four scenarios within the IAM framework, namely, 'Current Polices' (CPol), 'Nationally Determined Contributions' (NDC), 'Well Below 2 Degrees' (2C) and 'Toward 1.5 Degrees' (1.5C). A full description of these four scenarios and the modeling framework is presented in Section 3. Results on energy consumption and emissions are summarized in Section 4, followed by Section 5, which investigates the investment needs for fulfilling the low-carbon targets and other SDGs. Section 6 concludes with policy implications.

\section{Methods}

\subsection{MESSAGE modelling framework}

The IAM framework employed in this study, MESSAGEix-GLOBIOM, is a linear programming (LP) energy-economy-environment-engineering (4E) model with global coverage (Fricko et al., 2017; Huppmann et al., 2018; Krey et al., 2016). It is widely used for medium- to long-term energy system planning, energy policy analysis, and scenario development. The combined MESSAGE framework has global coverage and divides the world into 11 regions, among which 'Centrally Planned Asia and China' (CPA), 'South Asia' (SAS) and 'Other Pacific Asia' (PAS) cover all the developing Asian countries involved in this study. The detailed country definitions of the 11 MESSAGE regions can be found in the documentation of the model (Krey et al., 2016). To separate out the results of a single country such as China and India from their respective regions, we calculate the country's contribution to the total of the region with respect to GDP per capita over the whole timeframe, and then we multiply these share numbers with the variables related to energy consumption, $\mathrm{CO}_{2}$ emissions and investments of the model's native region values. This is a caveat, given the large differences in energy/carbon intensity 
and economic composition of different countries.

The MESSAGE framework's principal results comprise, among others, estimates of technologyspecific multi-sector response strategies for specific climate stabilization targets, such as well below $2{ }^{\circ} \mathrm{C}$. In the case of decarbonization pathways, the model identifies the least-cost portfolio of mitigation technologies, with the choice of the individual mitigation options across regions, fuels and sectors driven by the relative economics of the abatement measures, assuming full temporal and spatial flexibility (i.e., emissions-reduction measures are allowed to occur when and where they are cheapest to implement). Non-energy related investments (e.g. air pollution controls and food security) are not directly considered in the MESSAGE cost functions but are rather captured externally.

For estimating clean water and sanitation investments (SDG Targets 6.1, 6.2, 6.3, 6.4), we use an enhanced version of the MESSAGEix-GLOBIOM model that includes a reduced-form representation of the water supply sector (Parkinson et al., 2019; Parkinson et al., 2016). For air pollution (SDG Target 3.9), we use the GAINS model to estimate investments in air pollution control needed to comply with current legislation (Amann et al., 2011; Rafaj et al., 2018) . For food security (SDG Target 2.1), we calculate the cost of avoiding further increases in those at risk of hunger over and above the baseline (Fujimori et al., 2018; Hasegawa et al., 2018). More details on the models and methods are provided in the Supplementary Information.

\subsection{Scenario definition}

This study presents the results from four climate policy scenarios consistent with the Shared Socioeconomic Pathway SSP2, a 'middle-of-the-road' narrative for future socio-economic development, technological change and challenges to mitigation and adaptation (Fricko et al., 2017; He, 2017; O'Neill et al., 2017). The four globally comprehensive scenarios under the SSP2 Narrative explored in this study were originally defined within the framework of the CD-LINKS project (www.cdlinks.org) . 'Current Policies' (CPol) takes into account those energy- and climate-related policies that were already implemented by countries as of 2015. It serves as the reference case that reflects early efforts towards a low-carbon transition already implemented by policymakers in various parts of the world. The other three mitigation scenarios are 'Nationally Determined Contributions' (NDC), 'Well Below 2 Degrees' (2C) and 'Toward 1.5 Degrees' (1.5C), in which policies for low-carbon energy, energy efficiency and climate change mitigation are progressively tightened.

The NDC scenario assumes implementation of NDCs (conditional commitments) by 2030 in each 
country, followed by an equivalent effort over the post-2030 period. The $2 \mathrm{C}$ scenario aims to hold the maximum increase in global average temperatures to $2.0{ }^{\circ} \mathrm{C}$ (above the pre-industrial level) over the course of the twenty-first century with $>66 \%$ likelihood. Likewise but with higher stringency of mitigation policies, the $1.5 \mathrm{C}$ scenario aims to limit the temperature increase to $1.5^{\circ} \mathrm{C}$ in 2100 with $>50 \%$ likelihood (IPCC, 2018; Rogelj et al., 2015). Stylized mitigation policies are included in the form of carbon budgets to limit $\mathrm{CO}_{2}$ emissions from fossil fuel and industrial operations (FF\&I) to approximately 1,000 Gt over the 2011-2100 timeframe. Emissions mitigation (after 2020) occurs where and when it is most cost-effective; no burden-sharing regimes are in place. $\mathrm{CO}_{2}$ emissions presented in this paper include emissions from fossil fuel combustion and industry, but exclude land use. Cumulative $\mathrm{CO}_{2}$ emissions from fossil fuel combustion and industry over the historical period of 2011-2015 were roughly 163 billion tons $(\mathrm{Gt})(\mathrm{BP}, 2019)$. Model results then show that global cumulative emissions over the 2016-2100 timeframe are approximately $900 \mathrm{Gt}$ in the $2 \mathrm{C}$ scenario and $309 \mathrm{Gt}$ in the $1.5 \mathrm{C}$ scenario. Both of these numbers are in the lower half of the ranges in the IAM scenario literature (McCollum et al., 2018b).

\subsection{Definition of low-carbon energy}

Low-carbon energy in this study includes two aspects. On the supply-side are nuclear, renewables (solar, wind, hydro, biomass, geothermal), fossil fuel combustion equipped with carbon capture and storage (CCS), and the fraction of the electricity transmission and distribution investments that can be attributed to low-carbon electricity generation. On the demand-side is energy efficiency across the three end-use sectors (buildings, transport, industry).

\section{Energy consumption and $\mathrm{CO}_{2}$ emissions}

\subsection{Energy consumption patterns}

Stringent climate policies will have substantial impacts on patterns of energy supply and consumption globally, and these developments will undoubtedly constitute the core elements of the future energy transformation in developing Asia. Figure 2 illustrates these changes in primary energy (extraction and production) and secondary energy (electricity generation) between 2015 and 2050. The ranges of the results across six IAMs, including AIM/CGE, IMAGE, MESSAGEix-GLOBIOM, POLES, REMIND-MAgPIE and WITCH-GLOBIOM, are shown by the bar whiskers. The results of MESSAGE, 
as calculated in this study, are in the middle of the ranges.

The total magnitude of primary energy supply increases substantially by $32 \%$ between 2015 and 2030, and by 68\% between 2015 and 2050 in the CPol and NDC scenarios, as shown in Figure 2, Panel (a). In contrast, the $2 \mathrm{C}$ and $1.5 \mathrm{C}$ scenarios exhibit only a slight increase or stabilization of primary energy supply, indicating the trend of energy saving and efficient use alongside socioeconomic development. On top of that, fuel composition differs even more significantly across scenarios. In the CPol and NDC scenarios, coal still dominates primary energy consumption in 2030 and continues to occupy the largest share in 2050, despite a marked decline in absolute terms compared to 2015. On the contrary, the $2 \mathrm{C}$ scenario sees a pronounced shift toward renewable energy, which ultimately becomes a major contributor by 2050 . This role is further enhanced in the $1.5 \mathrm{C}$ scenario, in which renewable energy sources collectively constitute half of total primary energy by 2050 .

Figure 2, Panel (b) provides a detailed breakdown of the evolution of power generation technologies over time in the scenarios. In all cases, there is a significant shrinkage of coal without CCS from 2015 onward. This is true even in the $\mathrm{CPol}$ and NDC baselines, though certainly more so in the stringent $2 \mathrm{C}$ and $1.5 \mathrm{C}$ scenarios, which require a much faster coal phase out. In fact, in the $2 \mathrm{C}$ and $1.5 \mathrm{C}$ scenarios, our results indicate that all coal power plants would need to be effectively shut down by 2050 , in some instances before the end of their useful operating lifetime (i.e. early retirement). A large share of the avoided coal power is replaced by natural gas, particularly in the CPol and NDC baselines. In these baselines, low-carbon energy slightly increases from $35 \%$ in 2030 to $40 \%$ in 2050 . Then, in the $2 \mathrm{C}$ and $1.5 \mathrm{C}$ scenarios, this share rises much faster, reaching $61 \%$ and $78 \%$ in 2030 , respectively; by 2050 , the electricity mix becomes almost completely dominated by low-carbon technologies. As distribution of energy resources in Asia is highly imbalanced, an inter-regional and intra-regional grid connection within developing Asia, and also with the rest of the world, could be an important way of realizing largescale utilization of renewable energy resources. 

a. Primary energy consumption

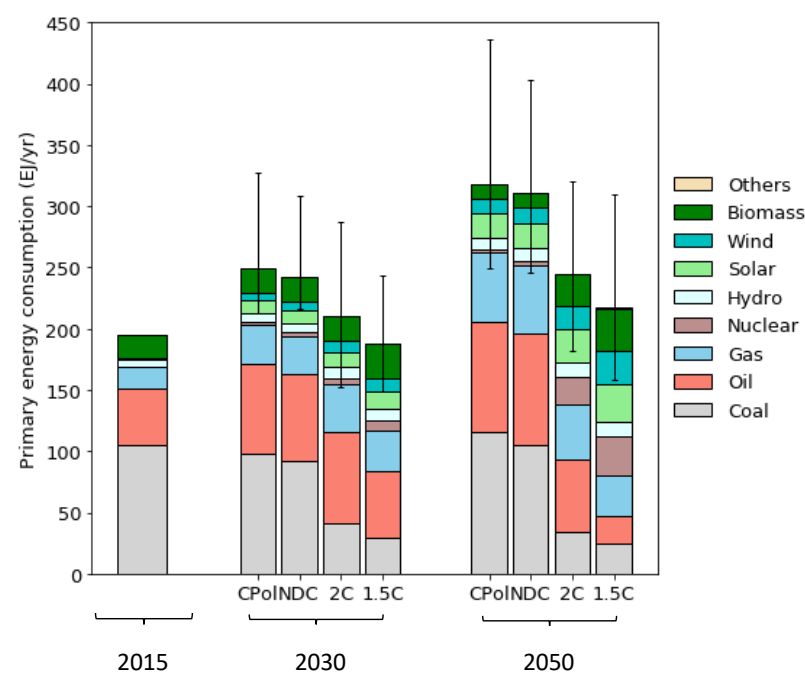

b. Electricity generation mix

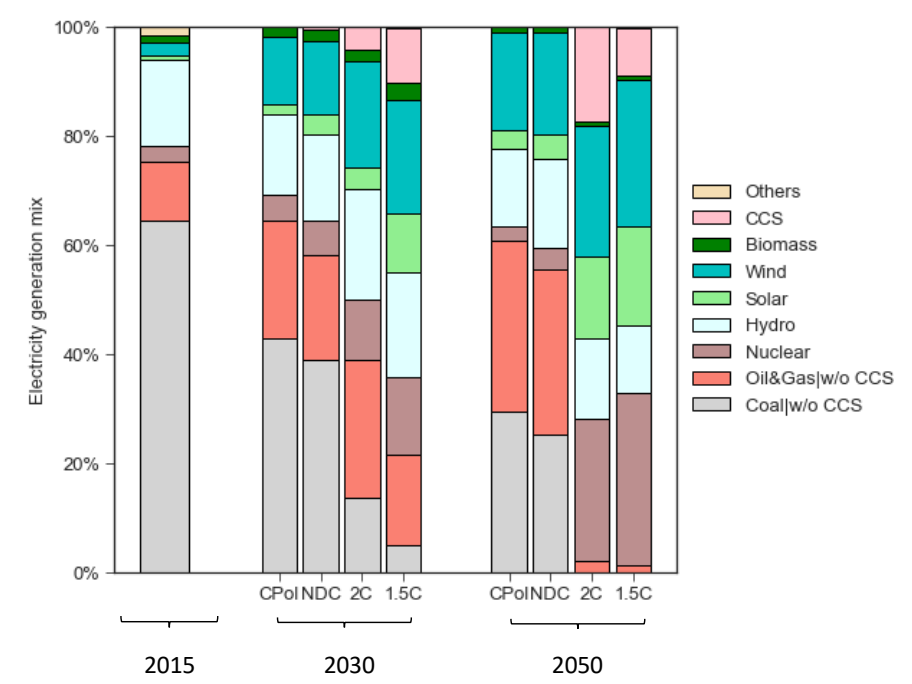

Fig. 2 Projected fuel composition of developing Asia's energy consumption from 2016 to 2050 under different scenarios. Panel (a): primary energy consumption, bar values represent the results of MESSAGE; bar whiskers give the minimum-maximum ranges across six IAMs (IIASA, 2019). Panel (b): electricity generation mix, in which CCS refers to electricity generated from coal, gas and biomassfueled power plants with CCS modules.

\section{2 $\mathrm{CO}_{2}$ emissions}

Owing to the underlying structural changes on the energy system side, the four scenarios exhibit remarkably differentiated $\mathrm{CO}_{2}$ emission pathways, as shown in Figure 3. Emissions across the four scenarios follow consistently either increasing pathways (CPol and NDC) or declining trends (2C and 1.5C). The baseline scenario witnesses a steady increase of emissions to 22,060 Mt/yr in 2050, which is only slightly higher than that of the NDC case. In contrast, the emissions in the $2 \mathrm{C}$ and $1.5 \mathrm{C}$ scenarios radically fall to 5,560 and 1,470 Mt/yr in 2050, respectively. It is interesting that the share of developing Asia's annual carbon emissions in the global total remains relatively stable across the four scenarios, roughly $40 \%$. Interestingly, the average annual emissions decline rate over the 25 -year period between 2015 and 2040 ( $-4.4 \%$ per year) is very close to the average growth rate over the 25 -year period between 1990 and 2015 (+5.3\% per year), with plateauing emission levels over the past several years representing this region's peak over the entire half-century timeframe.

Moreover, our results suggest the emissions intensity targets set by China and India in their NDCs can be reached in the four scenarios. While it is still too early to assert that China's carbon emissions have already reached their peak, many researchers argue the peaking time would come earlier under the 
economic development stage now known as "new normal" (He, 2017). One of the most direct causes is that, as some other studies point out, the peak of coal consumption in China may have already been reached as a result of economic growth being seemingly decoupled from coal use (IEA, 2018a; Jackson et al., 2015; Qi et al., 2016; Qiao et al., 2019), despite coal demand returning to growth slightly in 2017 and 2018.

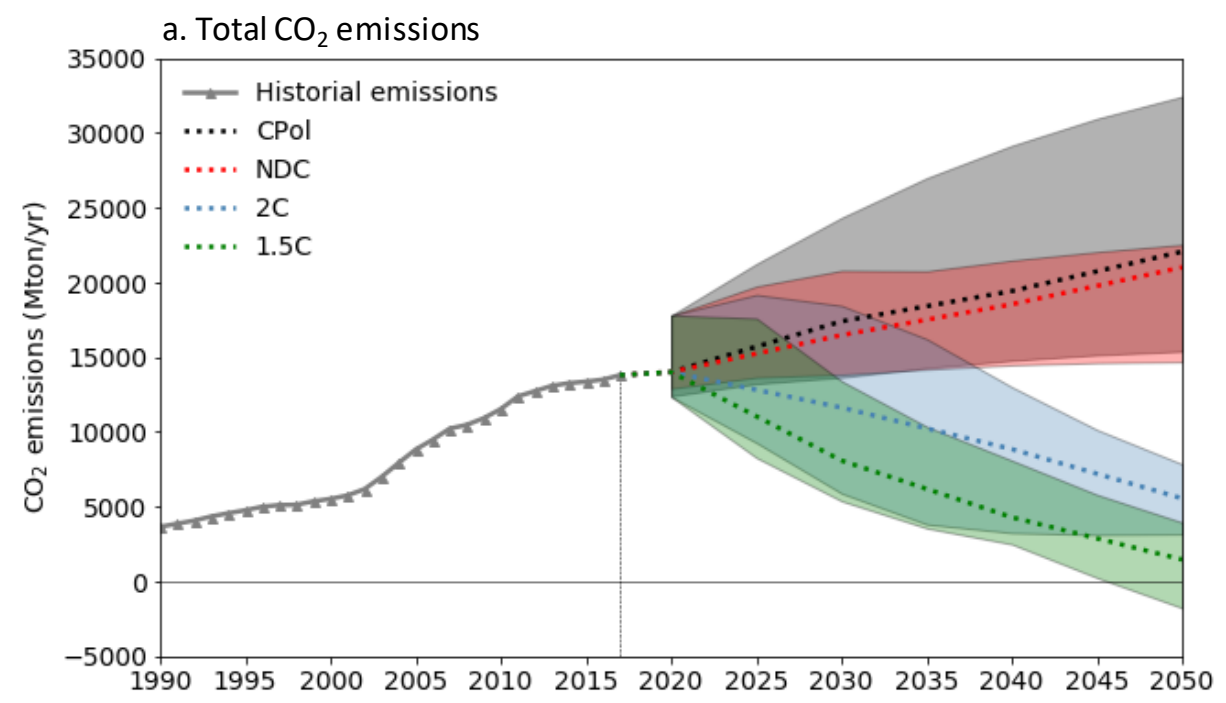

b. $\mathrm{CO}_{2}$ emissions of final energy sectors

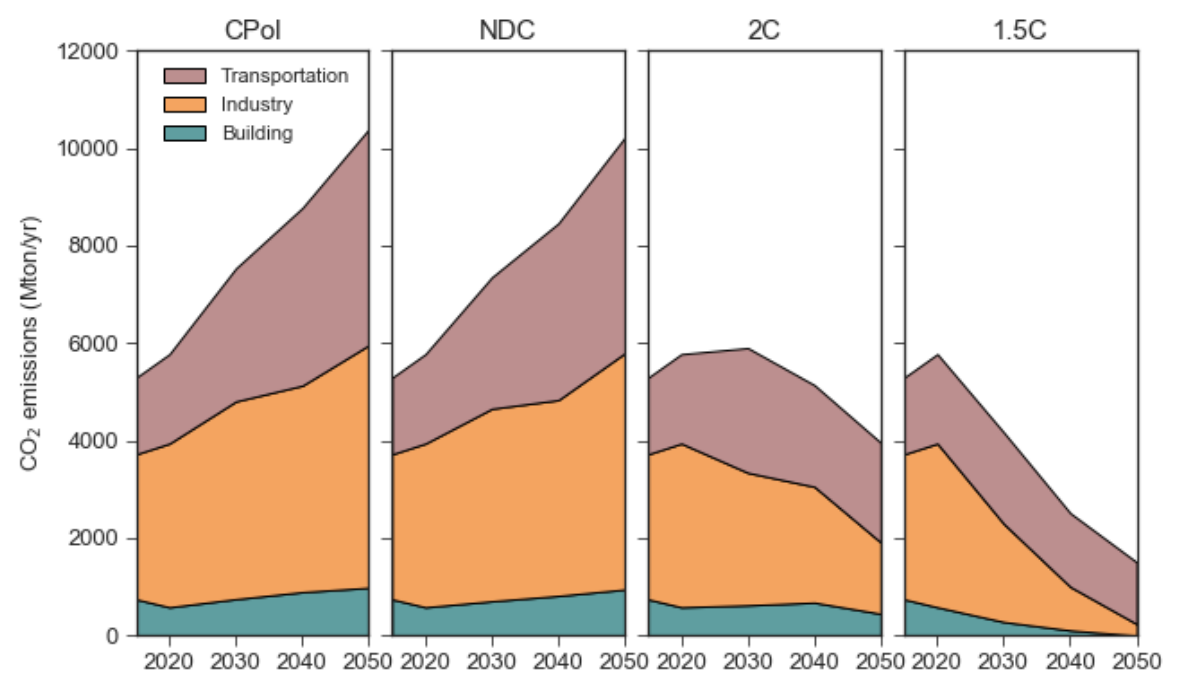

Fig. 3 Developing Asia's projected $\mathrm{CO}_{2}$ emissions to 2050. Panel (a) shows the historical $\mathrm{CO}_{2}$ emissions from 1990 to 2017, and the emissions of the scenarios calculated by the model as well, shading areas give the minimum-maximum ranges across six IAMs (IIASA, 2019; McCollum et al., 2018b). The historical data are obtained from BP statistics (BP, 2019). Panel (b) shows the emissions associated with final energy use in building, industry and transportation. Note that the sum of the emissions from these three sectors does not equal the total emissions, because a large portion of emissions occur in the process of upstream energy conversion, such as electricity generation and oil refining. 
Cumulative emissions over the period between 2016 and 2100 reach as high as 2,030 and 1,910 Gt respectively in the CPol and NDC cases (Table 1). When constrained by the global carbon budgets for the $2^{\circ} \mathrm{C}$ and $1.5^{\circ} \mathrm{C}$ targets, emissions would need to drop to $430 \mathrm{Gt}$ and $210 \mathrm{Gt}$, respectively, accounting for $47.5 \%$ and $67.3 \%$ of total global emissions in those scenarios. The finding that the developing Asia share is higher in the $1.5 \mathrm{C}$ than the $2 \mathrm{C}$ scenario shows that the more stringent the global climate policy, the greater the contribution of other countries to global mitigation efforts. As previously discussed, this result is driven by the model always searching for the least-cost mitigation measures across all countries and regions over the course of the century - and in this particular scenario exercise, without explicit consideration of mitigation effort-sharing schemes. One reason why mitigation activities take place more in other regions is because developing Asia, as a rapidly growing economy, sees more quickly rising labour and capital costs over the next several decades (and thus higher marginal abatement costs) relative to other emerging economies.

Table 1 Projected global and developing Asia's cumulative emissions between 2016 and 2100

\begin{tabular}{lllll}
\hline Scenario & $\begin{array}{l}\text { Developing } \\
\text { cumulative } \\
\text { between 2016 } \\
\text { (Gton) }\end{array}$ & $\begin{array}{r}\text { Asia's } \\
\text { emissions } \\
\text { and } 2100\end{array}$ & $\begin{array}{l}\text { Global } \\
\text { emissions between 2016 } \\
\text { and 2100 (Gton) }\end{array}$ & $\begin{array}{l}\text { cumulative } \\
\text { Asia's share }\end{array}$ \\
\hline CPol & 2025 & & 4878 & $41.2 \%$ \\
NDC & 1911 & 4605 & $41.5 \%$ \\
C & 428 & 900 & $47.5 \%$ \\
$1.5 C$ & 208 & 309 & $67.5 \%$ \\
\hline
\end{tabular}

The total volume of emissions in the three final energy sectors grows steadily in the baseline cases, but in contrast drops fast in the low carbon scenarios after reaching an initial peak. The ratio of the aggregated emissions from the three end-use sectors to the regional total emissions is substantially higher in the more stringent scenario. In 2050, this proportion is $52 \%, 79 \%$ and $95 \%$ respectively for the $\mathrm{CPol}, 2 \mathrm{C}$ and $1.5 \mathrm{C}$ scenarios. The results indicate drastic reduction of emissions in the energy conversion process in the low carbon scenarios, which is also demonstrated by the comparison of secondary energy mix shown in Figure 3, Panel (b).

In both the CPol and NDC scenarios, emissions from industry take the largest share over the whole period, though this share shrinks substantially, replaced largely by transportation. The absolute volume of industrial emissions undergoes a fast decline in the low-carbon scenarios, whereas emissions from 
the transportation sector remain relatively stable. The building sector, however, contributes the smallest portion of emissions among the three, as it features the highest portion of electricity in the energy mix.

\section{Investment needs}

\subsection{Energy investment needs}

As the world's largest market for energy investment at present, the volume of investment needed for developing Asia's low-carbon transition is also massive. The average annual investment results are shown in Figure 4, in which we separate the timespan into two periods, 2016-2030 and 2031-3050, representing the near-term and mid-term futures, respectively. Energy investment in this region reached US\$ 504 billion in 2015, accounting for $31 \%$ of the global total (IEA, 2016). Approximately half of these investments went into low-carbon sectors.

a. Investment needs for developing Asia

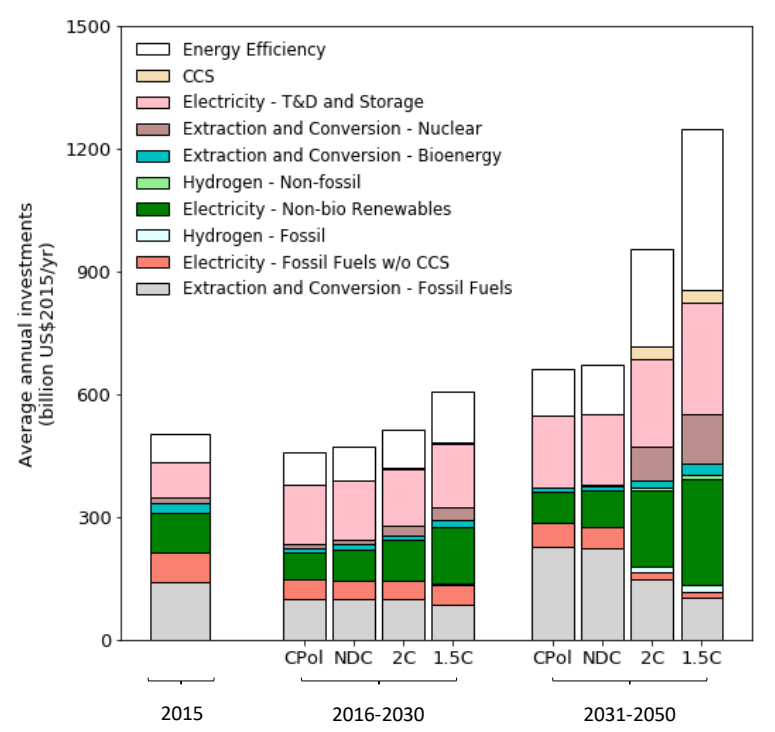

b. Investment needs for the three sub-regions

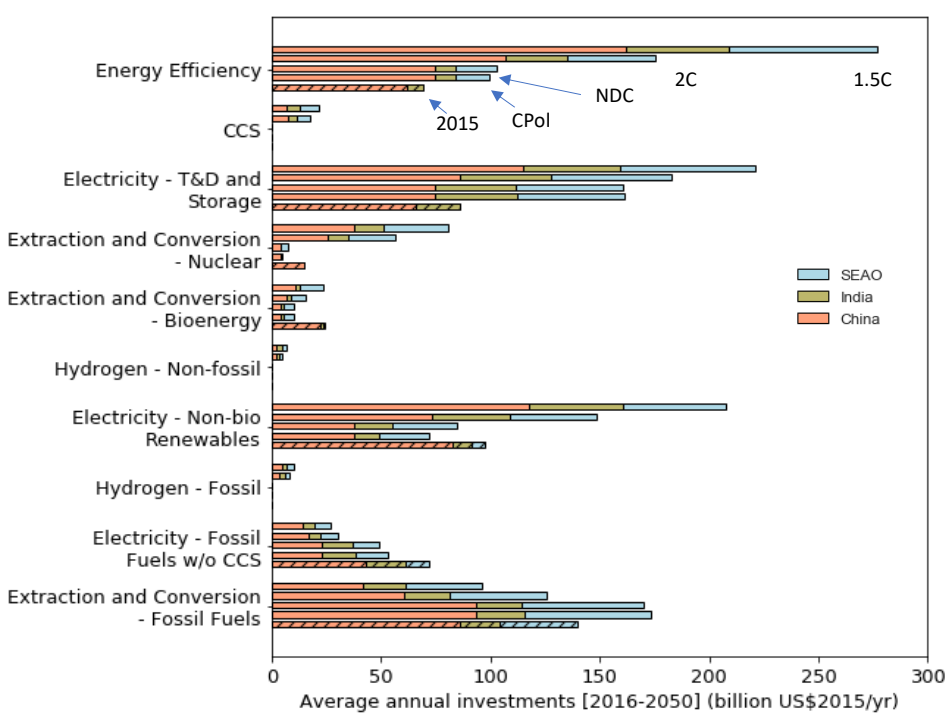

Fig. 4 Projected energy investments in developing Asia for different periods between 2016 and 2050. Panel (a) shows the whole region's investment needs under the four scenarios for different period. Panel (b) shows the investment needs for the three sub-regions, i.e., China, India and SEAO over the period between 2016 and 2050. The investment data for 2015 are obtained from World Energy Investment 2016 (IEA, 2016), and reorganized to the breakdown categories in this study.

In both future time periods, the magnitude of energy investment is larger in the low-carbon scenarios $(2 \mathrm{C}$ and $1.5 \mathrm{C})$ than in the baseline $(\mathrm{CPol}$ and $\mathrm{NDC})$; in particular, there is a remarkable shift towards low-carbon investments. For instance, during the period between 2016 and 2030, average annual 
investments in non-biomass renewable electricity (mainly solar and wind) increase from US\$ 60 billion in CPol to US\$ 100 billion in 2C and to US\$ 139 billion in 1.5C. This growth of renewables investment then becomes even more significant in the later period from 2031 to 2050, from US\$ 80 billion in CPol to US\$ 190 billion in 2C and US\$ 260 billion in 1.5C. Another striking change between the two periods is the sharp jump in energy efficiency investments in the low-carbon scenarios, which corresponds to a much lower final energy demand.

The results for the three sub-regions show that the current scale of investment into renewables in China, if retained for several decades, is consistent with what is needed for a $2^{\circ} \mathrm{C}$ consistent pathway; however, there is still an investment gap for the $1.5 \mathrm{C}$ scenario. Moreover, to achieve either the $2^{\circ} \mathrm{C}$ or $1.5^{\circ} \mathrm{C}$ targets, investment into energy efficiency needs to scale up markedly from today. The encouraging news is that, thanks to strong supporting policies for low-carbon technologies, investments into renewables and energy efficiency have soared over the past decade in parts of developing Asia, particularly China. In 2015, the low carbon share in China's total energy investment was approximately $51 \%$, notably higher than the global average level of 33\% (IEA, 2016), though still below some developed economies such as Europe. This level was then maintained in China in 2016 and 2017 (IEA, 2016,2017,2018b). However, the situation in India and SEAO is different: these countries would require significantly higher investment in all the low-carbon sectors in the $2 \mathrm{C}$ and $1.5 \mathrm{C}$ scenarios.

\subsection{Investment needs for other SDGs}

Some studies have indicated that the investments needed to drive forward the energy system transformation would also affect the investment requirements for fulfilling other energy-related SDGs (Hasegawa et al., 2018). To illustrate these effects using our modelling framework, we select three of these SDGs, that is, food security (SDG2), air pollution (SDG3), and clean water (SDG6), and measure the incremental investments relative to a reference case where these SDGs are achieved, but in the absence of an energy system transformation.

Figure 5 shows the relative changes of these indicators between 2016 and 2030 that are caused by transformations of the energy system consistent with the long-term climate targets of $2^{\circ} \mathrm{C}$ and $1.5^{\circ} \mathrm{C}$. The results illustrate that the total capital needs for climate change mitigation (SDG7 - affordable and clean energy) are significantly larger than the needs for making progress on other SDGs. It is also of note that China tends to dominate the investment needs for the multiple objectives, at least over the timeframe to 2030 presented here. 


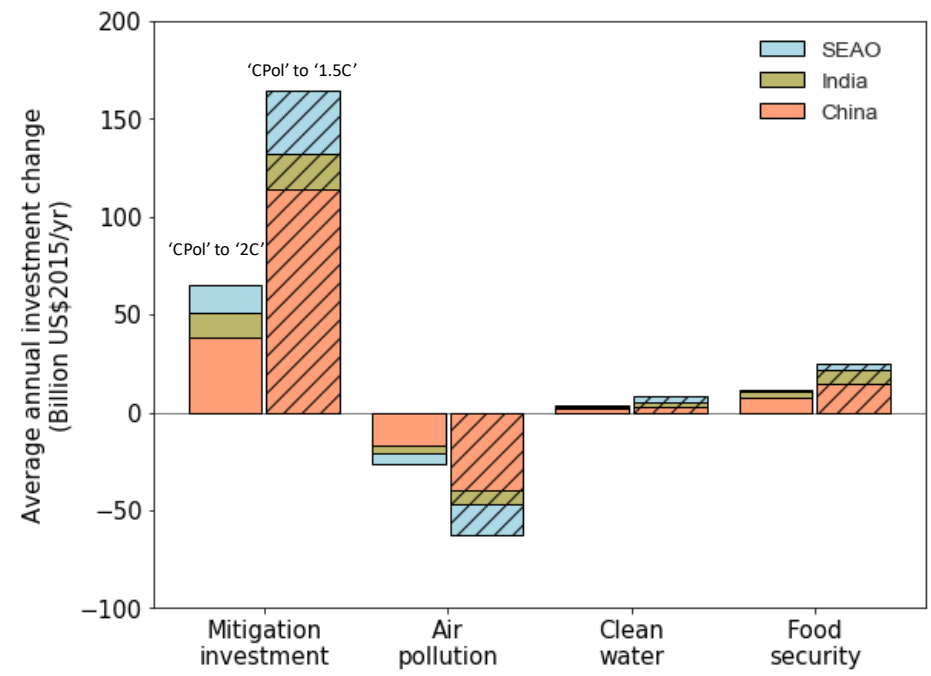

Fig. 5 Projected investment changes relative to the baseline over the period 2016-3030 for fulfilling the SDGs of air pollution, clean water, and food security in the context of an energy system transformation. The bars on the left side in each pair represent the investment changes of the $2 \mathrm{C}$ scenario relative to the $\mathrm{CPol}$ baseline; and the bars with hatches on the right side are those relative results for the $1.5 \mathrm{C}$ scenarios.

Our calculations demonstrate the considerable synergies between low-carbon investments and the capital needs for achieving the air pollution target (SDG 3.9 - By 2030, substantially reduce the number of deaths and illnesses from hazardous air pollution), that is, investment volumes of US\$ 26 and 63 billion per year can be saved under the $2 \mathrm{C}$ and $1.5 \mathrm{C}$ scenarios, respectively. The reason is that clean and efficient alternatives (such as solar and wind power, and electric vehicles) obviate the need for investing in expensive technologies for air pollution control as required by current legislation (Rafaj et al., 2018). On the other hand, water infrastructure is found to be little affected by an energy system transformation. Regarding food security, our results show increases of US\$ 12 billion and 25 billion per year to subsidize food goods in the $2 \mathrm{C}$ and $1.5 \mathrm{C}$ scenarios, respectively. This is consistent with findings from other studies, which point out that climate mitigation policies may also negatively affect food security, due to indirect impacts on prices and supplies of key agricultural commodities (Hasegawa et al., 2018; Hasegawa et al., 2015; Havlík et al., 2014).

\section{Conclusions}

Pursuing the stringent climate targets of the Paris Agreement and also the SDGs requires a fundamental transformation of the current energy system. Our results indicate that developing Asia's 
total primary energy supply could drop by approximately $23 \%$ and $31 \%$ in 2050 in scenarios that are in line with limiting global warming to $2^{\circ} \mathrm{C}$ and $1.5^{\circ} \mathrm{C}$, relative to the baseline case. The decrease is due entirely to a phase-out of fossil fuels, as low-carbon sources see increases of $79 \%$ and $140 \%$ in our modeled scenarios, respectively. On top of that, the fuel mix for electricity generation and final energy consumption becomes dominated by low-carbon energy.

This transformation throughout the whole energy system leads to a deep cut in carbon emissions by $75 \%$ and $92 \%$ in the $2 \mathrm{C}$ and $1.5 \mathrm{C}$ scenarios, respectively. To chart the course toward the two targets, the scale of investment into low-carbon energy and energy efficiency to 2050 needs to double in the $2 \mathrm{C}$ scenario and to triple in the $1.5 \mathrm{C}$ scenario, from the levels foreseen in the CPol baseline. Our results also reveal that low-carbon investment would significantly reduce the capital needs for achieving the SDG target for air quality, but would on the other hand increase the investment requirements for clean water and food security, though to a much smaller extent.

Among the three sub-regions, China dominates investments into low-carbon energy over the period, whereas the ratio of these investments to GDP is higher in India and SEAO than in China to 2050. At the moment, China is the world's largest investor in this sector, and in recent years, the country has been allocating more than half its total energy investment into low-carbon sectors (IEA, 2018b; IEA and IRENA, 2017), notably higher than the global average. The strong supporting policies that the government has implemented have been mobilizing a huge amount of investments into low-carbon technologies such as renewable energy and energy storage, which drives down the cost of these technologies in China (United Nations Envrionment Programme, 2018). Yet, despite these cost reductions, the development of many of the low-carbon industries still heavily relies on different forms of government fiscal support, such as subsidies or feed-in-tariffs. As a result, there is the risk that the investment volumes would probably shrink if these subsidies were weakened or removed, which incidentally is found to be happening now (China National Development and Reform Commission, 2016; China National Development and Reform Commission et al., 2018). This issue is even more severe for poorer regions such as India and SEAO. How these regions can mobilize sufficient investment to meet the massive gap for realizing low-carbon development in the coming decades remains a key question. Measures other than fiscal support (subsidies) should be explored in these contexts, including policies supporting green finance. This may help to mobilize a broadened channel of investment, in particular from the private sector, institutional investors, pension funds, insurance companies, sovereign wealth funds and mutual funds from either domestic or foreign sources (G20 Green Finance Study Group, 2017). These financial instruments and the associated investment risks have been widely 
discussed in the literature in recent years (Campiglio et al., 2018; G20 Green Finance Study Group, 2017; He, 2017). Making further progress on this front will require closer collaboration between researchers and scenario developers, policymakers and financial market participants. Novel and practical methodologies such as combining IAMs and other financial assessment tools would also play an important role in these efforts (UN Environment Finance Initiative, 2018).

\section{Acknowledgements}

This study was funded by the Global Energy Interconnection Group Corporation project (No. 52450018000Q), the World Bank, the Environment Research and Technology Development Fund (21908) of the Environmental Restoration and Conservation Agency, Japan, China's National R\&D Program (2016YFA0602602), China and Peter Kolp of IIASA is also recognized for his assistance with Web database development and support.

\section{References}

Amann, M., Bertok, I., Borken-Kleefeld, J., Cofala, J., Heyes, C., Höglund-Isaksson, L., Klimont, Z., Nguyen, B., Posch, M. and Rafaj, P. Cost-effective control of air quality and greenhouse gases in Europe: Modeling and policy applications. Environmental Modelling \& Software 26(12): 1489-1501. 2011.

Blanford, G. J., Rose, S. K. and Tavoni, M. Baseline projections of energy and emissions in Asia. Energy Economics 34: S284-S292. https://doi.org/10.1016/j.eneco.2012.08.006, 2012.

BP, Statistical Review of World Energy 2019. 2019.

Calvin, K., Clarke, L., Krey, V., Blanford, G., Jiang, K., Kainuma, M., Kriegler, E., Luderer, G. and Shukla, P. R. The role of Asia in mitigating climate change: Results from the Asia modeling exercise. Energy Economics 34: S251-S260. https://doi.org/10.1016/j.eneco.2012.09.003, 2012.

Campiglio, E., Dafermos, Y., Monnin, P., Ryan-Collins, J., Schotten, G. and Tanaka, M. Climate change challenges for central banks and financial regulators. Nature Climate Change 8(6): 462. 2018.

China Electricity Council, Statistics of China's Electric Power Industry 2017. 2018.

China National Bureau of Statistics. China Energy Statistical Yearbook. 2017.

China National Development and Reform Commission. China's Intended National Determined Contribution: Enhanced Actions on Climate Change. 2015.

China National Development and Reform Commission. Notice on adjusting the on-grid electricity prices of photovoltaic power generation and onshore wind power. 2016.

China National Development and Reform Commission, China Ministry of Finance and China National Energy Bureau. Notice on the related matters of solar electrcity generation. 2018.

Fricko, O., Havlik, P., Rogelj, J., Klimont, Z., Gusti, M., Johnson, N., Kolp, P., Strubegger, M., Valin, H. and Amann, M. The marker quantification of the Shared Socioeconomic Pathway 2: a middle-of-the-road scenario for the 21st century. Global Environmental Change 42: 251-267. 2017.

Fujimori, S., Hasegawa, T., Rogelj, J., Su, X., Havlik, P., Krey, V., Takahashi, K. and Riahi, K. Inclusive climate change mitigation and food security policy under $1.5^{\circ} \mathrm{C}$ climate goal. Environmental Research Letters 13(7): 074033. 2018.

Fujimori, S., Kainuma, M. and Masui, T.Post-2020 Climate Action: Global and Asian Perspectives. Springer. 2017.

G20 Green Finance Study Group, G20 Green Finance Synthesis Report 2017. 2017. http://unepinquiry.org/wpcontent/uploads/2016/09/Synthesis_Report_Full_EN.pdf

Guan, D., Meng, J., Reiner, D. M., Zhang, N., Shan, Y., Mi, Z., Shao, S., Liu, Z., Zhang, Q. and Davis, S. J. Structural decline 
in China's $\mathrm{CO}_{2}$ emissions through transitions in industry and energy systems. Nature Geoscience 11(8): 551-555. 10.1038/s41561-018-0161-1, 2018.

Hasegawa, T., Fujimori, S., Havlík, P., Valin, H., Bodirsky, B. L., Doelman, J. C., Fellmann, T., Kyle, P., Koopman, J. F. and Lotze-Campen, H. Risk of increased food insecurity under stringent global climate change mitigation policy. Nature Climate Change 8(8): 699. 2018.

Hasegawa, T., Fujimori, S., Shin, Y., Tanaka, A., Takahashi, K. and Masui, T. Consequence of climate mitigation on the risk of hunger. Environmental science \& technology 49(12): 7245-7253. 2015.

Havlík, P., Valin, H., Herrero, M., Obersteiner, M., Schmid, E., Rufino, M. C., Mosnier, A., Thornton, P. K., Böttcher, H., Conant, R. T., Frank, S., Fritz, S., Fuss, S., Kraxner, F. and Notenbaert, A. Climate change mitigation through livestock system transitions. Proceedings of the National Academy of Sciences 111(10): 3709-3714. 10.1073/pnas.1308044111, 2014. He, J. Low carbon transformation under the new normal. Journal of Environmental Economics (in Chinese) 2(1): 1-6. 2017. $\mathrm{He}$, J., Deng, J. and Su, M. CO ${ }_{2}$ emission from China's energy sector and strategy for its control. Energy 35(11): 4494-4498. https://doi.org/10.1016/j.energy.2009.04.009, 2010.

Huppmann, D., Gidden, M., Fricko, O., Kolp, P., Orthofer, C., Pimmer, M., Vinca, A., Mastrucci, A., Riahi, K. and Krey, V. The MESSAGEix Integrated Assessment Model and the ix modeling platform (ixmp). Environmental Modelling \& Software: in press. 2018.

IEA, World Energy Investment 2016. 2016.

IEA, World Energy Investment 2017. 2017.

IEA, Coal 2018: Analysis and Forecasts to 2023. https://doi.org/10.1787/25202723, 2018a.

IEA, World Energy Investment 2018. 2018 b.

IEA, World Energy Investment 2019. 2019. https://www.iea.org/reports/world-energy-investment-2019

IEA and IRENA, Perspectives for the Energy Transition: Investment Needs for a Low-carbon Energy System. 2017.

IIASA. IAMC $1.5^{\circ} \mathrm{C}$ Scenario Explorer. 2019. https://data.ene.iiasa.ac.at/iamc-1.5c-explorer

IPCC, IPCC Special Report on Global Warming of $1.5^{\circ} \mathrm{C} .2018$.

Jackson, R. B., Canadell, J. G., Le Quéré, C., Andrew, R. M., Korsbakken, J. I., Peters, G. P. and Nakicenovic, N. Reaching peak emissions. Nature Climate Change: 1-7. 2015.

Korsbakken, J. I., Peters, G. P. and Andrew, R. M. Uncertainties around reductions in China's coal use and $\mathrm{CO}_{2}$ emissions. Nature Climate Change 6(7): 687-690. 2016.

Krey, V., Havlik, P., Fricko, O., Zilliacus, J., Gidden, M., Strubegger, M., Kartasasmita, G., Ermolieva, T., Forsell, N., Gusti, M., Johnson, N., Kindermann, G., Kolp, P., McCollum, D. L., Pachauri, S., Rao, S., Rogelj, J., Valin, H., Obersteiner, M. and Riahi, K., International Institute for Applied Systems Analysis. MESSAGE-GLOBIOM 1.0 Documentation. 2016. http://data.ene.iiasa.ac.at/message-globiom/

McCollum, D. L., Echeverri, L. G., Busch, S., Pachauri, S., Parkinson, S., Rogelj, J., Krey, V., Minx, J. C., Nilsson, M. and Stevance, A.-S. Connecting the sustainable development goals by their energy inter-linkages. Environmental Research Letters 13(3): 1-23. 2018a.

McCollum, D. L., Zhou, W., Bertram, C., De Boer, H.-S., Bosetti, V., Busch, S., Després, J., Drouet, L., Emmerling, J. and Fay, M. Energy investment needs for fulfilling the Paris Agreement and achieving the Sustainable Development Goals. Nature Energy 3(7): 589. 2018b.

Mi, Z., Meng, J., Guan, D., Shan, Y., Liu, Z., Wang, Y., Feng, K. and Wei, Y.-M. Pattern changes in determinants of Chinese emissions. Environmental Research Letters 12(7): 074003. 2017.

Mittal, S., Dai, H., Fujimori, S. and Masui, T. Bridging greenhouse gas emissions and renewable energy deployment target: comparative assessment of China and India. Applied Energy 166: 301-313. 2016.

O’Neill, B. C., Kriegler, E., Ebi, K. L., Kemp-Benedict, E., Riahi, K., Rothman, D. S., van Ruijven, B. J., van Vuuren, D. P., Birkmann, J. and Kok, K. The roads ahead: narratives for shared socioeconomic pathways describing world futures in the 21st century. Global Environmental Change 42: 169-180. 2017.

Parkinson, S., Krey, V., Huppmann, D., Kahil, T., McCollum, D., Fricko, O., Byers, E., Gidden, M. J., Mayor, B. and Khan, Z. Balancing clean water-climate change mitigation trade-offs. Environmental Research Letters 14(1): 014009. 2019.

Parkinson, S. C., Johnson, N., Rao, N. D., Jones, B., van Vliet, M. T., Fricko, O., Djilali, N., Riahi, K. and Flörke, M. Climate and human development impacts on municipal water demand: A spatially-explicit global modeling framework. Environmental Modelling \& Software 85: 266-278. 2016.

Qi, Y., Stern, N., Wu, T., Lu, J. and Green, F. China's post-coal growth. Nature Geoscience 9(8): 564-566. 2016.

Qiao, H., Chen, S., Dong, X. and Dong, K. Has China's coal consumption actually reached its peak? National and regional analysis considering cross-sectional dependence and heterogeneity. Energy Economics 84: 104509. https://doi.org/10.1016/j.eneco.2019.104509, 2019.

Rafaj, P. and Amann, M. Decomposing air pollutant emissions in Asia: Determinants and projections. Energies 11(5): 1299. 2018.

Rafaj, P., Kiesewetter, G., Gül, T., Schöpp, W., Cofala, J., Klimont, Z., Purohit, P., Heyes, C., Amann, M., Borken-Kleefeld, 
J. and Cozzi, L. Outlook for clean air in the context of sustainable development goals. Global Environmental Change 53: 111. https://doi.org/10.1016/j.gloenvcha.2018.08.008, 2018.

Rogelj, J., Luderer, G., Pietzcker, R. C., Kriegler, E., Schaeffer, M., Krey, V. and Riahi, K. Energy system transformations for limiting end-of-century warming to below 1.5 C. Nature Climate Change 5(6): 519-527. 2015.

UN Environment Finance Initiative, Extending our horizons: Assessing credit risk and opportunity in a changing climate Outputs of a working group of 16 banks piloting the TCFD Recommendations. 2018. http://www.unepfi.org/wordpress/wpcontent/uploads/2018/04/EXTENDING-OUR-HORIZONS.pdf

UNFCCC, India's Intended Nationally Determined Constribution: Working Towards Climate Justice. 2015.

United Nations Envrionment Programme, B. N. E. F., Frankfurt School FS-UNEP Collaborating Center, Global Trends in Renewable Energy Investment 2018. 2018.

World Bank, World Bank Open Data. 2018.

Zhang, W., Li, K., Zhou, D., Zhang, W. and Gao, H. Decomposition of intensity of energy-related $\mathrm{CO}_{2}$ emission in Chinese provinces using the LMDI method. Energy Policy 92: 369-381. 2016.

Zhang, X., Karplus, V. J., Qi, T., Zhang, D. and He, J. Carbon emissions in China: How far can new efforts bend the curve? Energy Economics 54: 388-395. https://doi.org/10.1016/j.eneco.2015.12.002, 2016. 